\title{
Agradecimiento a revisores de manuscritos médicos de la revista Anales Médicos
}

La evaluación de los manuscritos médicos es esencial para determinar su relevancia, pertinencia y validez académica. Médicos en distintas especialidades y profesionistas de otras disciplinas afines a la medicina llevan a cabo esta labor, quienes, de forma desinteresada, dedican gran parte de su valioso tiempo y conocimiento a dicha tarea.

La revisión de los manuscritos se efectúa sin saber a quién se evalúa; esta labor se complementa con la disposición de los autores a corregir y mejorar sus trabajos e incorporar en ellos las recomendaciones señaladas por su revisor, cuya identidad también se desconoce. Este círculo de trabajo produce los artículos publicados en la revista Anales Médicos.

Nos sentimos profundamente agradecidos con los siguientes revisores:

Ablanedo Terrazas Yuria Ayala Gamboa Ubaldo Ayala Yáñez Rodrigo Bross Soriano Daniel Cendón Ortega María Mercedes Chirino Barceló Yazmín Amelia Collado Corona Miguel Ángel Collado Ortiz Miguel Ángel Felemovicius Hermangus Jacobo Fernández Vázquez Juan Manuel
Hoyo Ulloa Irma López Velarde Badager Pedro Montiel Herrera Juan Manuel Mota Sanhua Vanessa Mussan Chelminsky Gil Rodríguez Weber Gabriel Serrano Ardila Ana Soto López María Elena Taylor Martínez Mario Alberto Zamorano Jiménez Clara Aurora 